\title{
EFEITO DE NÍVEIS CRESCENTES DE LEVEDURA DE ÁLCOOL EM RAÇÕES CONTENDO FÍGADO BOVINO SOBRE A PERFORMANCE DE LARVAS DE JUNDIÁ (Rhamdia quelen) ${ }^{1}$
}

\author{
EFFECT OF CRESCENT LEVELS OF YEAST OF ALCOHOL USED IN RATIONS \\ CONTAINING BOVINE LIVER ON LARVAE OF \\ (Rhamdia quelen) PERFORMANCE
}

\author{
Rosamari Piaia $^{2}$ João Radünz Neto ${ }^{3}$
}

RESUMO

O presente trabalho foi realizado com a finalidade de avaliar o efeito de diferentes níveis de levedura sobre o desempenho inicial de larvas de Rhamdia quelen durante as três primeiras semanas de vida. Um total de 3000 larvas foram distribuídas em quinze grupos, em um sistema de criação com re-utilização de água, termoregulada. Utilizou-se cinco tratamentos com níveis crescentes de levedura $(T 1-50 \%, T 2$ 60\%, T3 - 70\%, T4 - 80\% e T5 - 90\%) em substituição ao fígado bovino fresco. Os níveis de proteína bruta $(P B)$ e energia digestível variaram de 41,36 a 26,56\% de PB e 3197 a $2789 \mathrm{kcal}$ ED/kg. A granulometria dos alimentos testados foi de 100 a $200 \mu, 200$ a $400 \mu$ e 400 a $600 \mu$ para as três semanas experimentais, respectivamente. $O$ alimento foi fornecido à vontade entre 8 e 20 horas. Dentro dos limites de proteína estudados houve efeito positivo de níveis mais elevados de $P B$ sobre os comprimentos total e padrão e peso individual. Porém houve um efeito negativo sobre a sobrevivência das larvas de jundiá Rhamdia quelen.

Palavras-chave: dieta, figado, levedura, sobrevivência.

SUMMARY

The present study was developed with the purpose of evaluating the effects of different protein levels in initial performance of Rhamdia quelen larvae during the first three weeks of life. The sample contained 3000 larvae distributed in fifteen groups, maintained in controlled conditions of culture and utilizing termoregulatory water re-use system. Five crescent levels of yeast (T1 50\%, T2 60\%, T3 70\%, T4 80\% and T5 90\%) were used in rations in substituition of bovine liver. Levels of crude protein and digestible energy varied $41,36 \%$ to $26,56 \% \mathrm{CP}$ and from 3197 to $2789 \mathrm{kcal} \mathrm{ED/kg}$. The granulometry of tested food was of $100 \mathrm{a}$ $200 \mu, 200 a 400 \mu$ and 400 a $600 \mu$ for three experimental weeks respectively. Food distribution provided at ease between $8 \mathrm{Am}$ and $8 \mathrm{Pm}$. Within the net protein used in this research, there was found a positive effect for the highest protein levels for total, standard lenght and individual weight while, it was observed a negative effect over the larval survival of jundiá Rhamdia quelen.

Key words: diet, liver, survival, yeast.

\section{INTRODUÇÃO}

Durante o estágio inicial de desenvolvimento de larvas de peixes, o crescimento potencial é extremamente alto e a troca de alimentação endógena (reservas vitelinas) para alimento exógeno é o estágio mais importante para o ciclo de vida dos teleósteos. Até o presente, poucos dados precisos sobre os requerimentos nutricionais para os primeiros

\footnotetext{
${ }^{1}$ Parte da Dissertação de Mestrado apresentada pelo primeiro autor junto ao Curso de Pós-graduação em Zootecnia da Universidade Federal de Santa Maria - UFSM.

${ }^{2}$ Bióloga, Mestre em Zootecnia.

${ }^{3}$ Engenheiro Agrônomo, Doutor, Professor Adjunto do Departamento de Zootecnia, UFSM, Camobi, 97119-900 - Santa Maria, RS. Autor para correspondência.
} 
estágios de desenvolvimento de larvas. Para algumas espécies de água doce as técnicas de criação de larvas está se desenvolvendo. Este fato abre a perspectiva do uso de dietas artificiais para a primeira alimentação sem o uso de qualquer forma de alimento vivo (KAUSHIK, 1988).

Com a finalidade de aumentar a produção de peixes, alguns trabalhos nutricionais foram realizados na Argentina e no Uruguai com alevinos de bagre sul-americano Rhamdia sapo por LUCHINI \& SALAS (1984) e VARELA et al. (1983), respectivamente. No Brasil, SANTOS et al. (1988) trabalharam com larvas da mesma espécie e PIAIA et al. (1995) com larvas de jundiá Rhamdia quelen constatando a aceitação do alimento artificial. No entanto, a alimentação larval de espécies nativas ainda precisa ser melhorada, visando obter alevinos viáveis e com alta taxa de sobrevivência. Os produtos testados são variados, mas os mais eficazes têm sido as leveduras e fígado bovino (CHARLON \& BERGOT, 1984; SZLAMINSKA et al., 1990; RADÜNZ NETO $\boldsymbol{e}$ t $\boldsymbol{a}$ l. (1993); LEGENDRE et al., 1995).

O objetivo deste trabalho foi avaliar o efeito de diferentes quantidades de levedura, e consequiente variação dos níveis de $\mathrm{PB}$, sobre o desempenho inicial de larvas do jundiá Rhamdia quelen.

\section{MATERIAIS E MÉTODOS}

O presente trabalho foi conduzido, durante o mês de dezembro de 1995, no Setor de Piscicultura do Departamento de Zootecnia, Centro de Ciências Rurais da Universidade Federal de Santa Maria (UFSM), com duração de 21 dias.

$$
\text { Como instalações }
$$
experimentais utilizou-se um sistema de re-circulação d'água, termoregulada, acoplado a um biofiltro, descrito por CHARLON \& BERGOT (1984). Este sistema possui 16 unidades de criação feitas em fibra de vidro. Cada unidade é constituída de duas bacias, uma externa medindo $38 \times 38$ x $15 \mathrm{~cm}$, e uma interna medindo $33 \times 33 \times 13 \mathrm{~cm}$ que possuem uma capacidade de 8 litros de água. A unidade interna é dotada de uma tela a qual permite a saída d'água. Estes reservatórios foram abastecidos individualmente e a vazão d'água utilizada foi de 0,2 ; 0,4 e $0,61 /$ minuto, respectivamente, na primeira, segunda e terceira semana experimental. Durante todo o período experimental a temperatura foi mantida em $23 \pm 1,0^{\circ} \mathrm{C}$. O valor de oxigênio dissolvido na água foi tomado diariamente, representando em média 7,7 $\pm 0,5 \mathrm{mg} / \mathrm{l}$.

Foram testados níveis crescentes de incorporação de levedura de álcool em substituição ao fígado bovino cru, redundando em dietas com níveis decrescentes de proteína bruta (Tabela 1). Os valores protéicos e energéticos das matérias primas foram descritos por FIALHO (1983) e CHURCH \& POND (1974). Os valores das vitaminas foram baseados nos requerimentos para carpa, e os valores em minerais

labela 1 - Lormponģao das raçoes expenmentals utuzadas na alumentesao de larvas de jưdiá Rhamdia quelen.

\begin{tabular}{|c|c|c|c|c|}
\hline $\begin{array}{l}\text { TRATA- } \\
\text { MENTO }\end{array}$ & $\% \mathrm{~PB}$ & lccal ED/lig & INGREDIENTES & $\%$ \\
\hline T1 & 41,44 & 3197 & $\begin{array}{l}\text { Pó de lavedura } \\
\text { Fígado boviro on (MS) } \\
\text { Farelo de arroz desengomburado } \\
\text { Prerrix vitarínico } \\
\text { Fosfato bicálciro }\end{array}$ & $\begin{array}{r}50,0 \\
40,0 \\
8,0 \\
1,5 \\
0,5\end{array}$ \\
\hline $\mathrm{T} 2$ & 37,66 & 3095 & 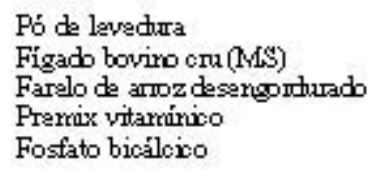 & $\begin{array}{r}60,0 \\
30,0 \\
8,0 \\
1,5 \\
0,5\end{array}$ \\
\hline \multirow{3}{*}{$\mathrm{T} 3$} & & & $\begin{array}{l}\text { Pó de lavedura } \\
\text { Figad boviro cru (MS) }\end{array}$ & $\begin{array}{l}70,0 \\
20,0\end{array}$ \\
\hline & 33,06 & 2093 & $\begin{array}{l}\text { Farelo de amoz desengombrado } \\
\text { Prerrix vitarrínico } \\
\text { Fosfato bicílcico }\end{array}$ & $\begin{array}{l}8,0 \\
1,5 \\
0,5\end{array}$ \\
\hline & & & $\begin{array}{l}\text { Pó de lavedura } \\
\text { Fígado boviro cru (MS) }\end{array}$ & $\begin{array}{l}80,0 \\
10,0\end{array}$ \\
\hline T4 & 30,26 & 2801 & $\begin{array}{l}\text { Farelo de arroz desengonturado } \\
\text { Prerrix vitarnínico } \\
\text { Fosta to bicálcico }\end{array}$ & $\begin{array}{l}8,0 \\
1,5 \\
0,5\end{array}$ \\
\hline TS & 26,64 & 2780 & $\begin{array}{l}\text { Pó de lavedura } \\
\text { Farelo de armoz desengombuado } \\
\text { Prerrix vitarúnico } \\
\text { Fostato bicalcico }\end{array}$ & $\begin{array}{l}90,0 \\
8,0 \\
1,5 \\
0,5\end{array}$ \\
\hline
\end{tabular}

${ }^{1}$ Composição da ruistura vitarúrica segurdo o fabricante (Comparhia Miruano de Alimentos) - Niveisllgg do produto: Vit. $\mathrm{A}=5.500 .000 \mathrm{UI}$, Vit. $\mathrm{B}=1.500 .000 \mathrm{UI}$, Vit. $\mathrm{E}=12.500 \mathrm{mg}$. Vit. $\mathrm{K}=1.750 \mathrm{mg}$ Vit. $\mathrm{B}=1500 \mathrm{mg}$. Vit. $\mathrm{B}=3.000 \mathrm{mg}$ Vit. $\mathrm{B}=1750 \mathrm{mg}$

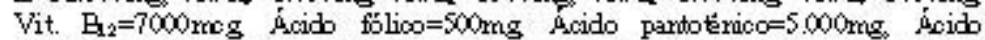
ricotírico $=17.500 \mathrm{mg}$ Biotina $=75 \mathrm{mg}$. Cbreto de colina $=125000 \mathrm{mg}$ DL Metionina $=300.000 \mathrm{mg}$ e Artioxilanto $=7.500 \mathrm{mg}$ 
seguiram requerimentos para o bagre americano (Ictalurus punctatus), segundo HEPHER (1990). O premix vitamínico utilizado era pré-fabricado, formulado para aves. A quantidade de vitamina $\mathrm{C}$ (ácido ascórbico) utilizada foi de $300 \mathrm{mg} / \mathrm{kg}$, recomendada por LI \& LOVELL (1985) para o bagre americano (Ictalurus punctatus).

Para a preparação das rações, os ingredientes secos foram triturados, separadamente em moinho para grãos e peneirados de modo a se obter uma granulometria menor que $75 \mu$ e a fração de fígado bovino fresco foi moída. Após a pesagem, os ingredientes foram misturados para completa homogeneização e certa quantidade de água destilada (máximo de 30\%) foi adicionada à mistura até adquirir a consistência desejada. As rações foram, então, passadas em máquina de moer carne e em seguida secas ao ambiente natural ( $\mathrm{sol}$ ) por 8 horas. A temperatura na superfície do alimento esteve em 36oC. A temperatura média do ar manteve-se em torno de 18,4 oC e a média da umidade relativa do ar foi de $67 \%$, segundo dados fornecidos pela estação metereológica do Departamento de Fitotecnia da UFSM. Após a secagem, cada ração foi triturada e peneirada, sendo recuperadas partículas de 100 a $200 \mu, 200$ a $400 \mu$ e 400 a $600 \mu$ para a $1^{a}, 2^{a}$ e $3^{a}$ semanas, respectivamente, utilizadas segundo RADÜNZ NETO et al. (1993) para larvas de carpa Cyprinus carpio.

Diariamente, o alimento foi oferecido à vontade às larvas a cada meia hora entre 8:00 e 20:00 horas, formando uma fina camada que flutuava sobre a superfície da água. Foi utilizado um fotoperíodo de 12 horas, utilizando-se lâmpadas fluorescentes.

A troca de granulometria foi realizada semanalmente, logo após a retirada de amostra das larvas para avaliação de medidas de comprimento.

Diariamente foi feita limpeza das bacias, para a retirada de peixes mortos, excrementos fecais e sobra de ração acumulada. Para isto, realizou-se a transferência das larvas para as bacias limpas, através da inclinação da bacia interna, possibilitando desta forma que o material orgânico ficasse retido nas paredes e permitindo que as larvas sobrenadantes fossem transferidas para o novo reservatório. Após, com o uso de um objeto de sucção, foram retiradas as eventuais sobras de material suspenso na água, possibilitando desta forma uma limpeza mais completa.

Os parâmetros estimados foram:

- Índice de mortalidade, anotado diariamente;
- Comprimento padrão (CP) e comprimento total (CT) tomados sobre uma amostra de 10 larvas de cada unidade experimental, a cada 7 dias;

- Peso médio individual (PMI) calculado em função do peso total das larvas de cada unidade experimental, dividido pelo número de peixes sobreviventes no final do experimento.

- Produto do peso versus sobrevivência (P x S), obtido através do peso médio individual versus sobrevivência, para avaliar a biomassa total das larvas por tratamento.

O delineamento experimental foi o inteiramente casualizado com cinco tratamentos e três repetições.

Os dados obtidos foram submetidos à análise de regressão, utilizando-se o programa SAS (1989), através do sistema operacional CMS.

\section{RESULTADOS E DISCUSSÃO}

Os dados obtidos com relação ao crescimento (CT e $\mathrm{CP})$ mostram que os maiores peixes aos 21 dias são aqueles do tratamento T1 (50\% levedura mais $40 \%$ fígado; Tabela 2). A análise de regressão indica que o nível de proteína na ração influenciou o comprimento total nas três datas coletadas. Houve um aumento médio de $0,099 \mathrm{~mm}$ para cada $1 \%$ a mais de proteína na ração aos sete dias até $1,443 \mathrm{~mm}$ aos 21 dias (Tabela 3).

O tratamento T5 apresentou larvas com CT aos 21 dias igual a $10,5 \mathrm{~mm}$. Este valor é inferior aos encontrados por RADÜNZ NETO et al. (1993) com larvas de carpa quando obtiveram CT aos 21 dias igual a 19,2; 17,3 e 16,7mm em três experimentos utilizando alimentos com $80 \%$ de levedura.

Os valores dos tratamentos $\mathrm{T} 1 \mathrm{e} \mathrm{T} 2$ foram superiores aos encontrados por RADÜNZ NETO $\boldsymbol{e} t$ al. (1993) obtendo26,6mm de CT para a fórmula 50\% levedura e $35 \%$ fígado bovino aos 28 dias, e também aos encontrados por SZLAMINSKA et al. (1991) para a fórmula $58 \%$ levedura e $24 \%$ de fígado bovino, obtendo $23 \mathrm{~mm}$ CT no final de 21 dias para as larvas de Carassius auratus.

Os índices de sobrevivência obtidos foram superiores a $50 \%$ (Tabela 2), sendo que os mais elevados foram dos tratamentos contendo entre $60 \mathrm{e}$ $80 \%$ de levedura. Tanto acima, como abaixo destes níveis, a percentagem de sobrevivência foi menor. Pela análise de regressão (Tabela 3 ) constatou-se que a sobrevivência diminuiu 1,006 a cada $1 \%$ a mais de proteína na ração, nos alimentos fígado mais levedura. O valor obtido com o tratamento T5 (90\% levedura) igual a $66,66 \%$ é inferior aos encontrados por 
Tabela 2 - Valores médios de comprimento total (CT) e padrão (CP), sobrevivência (SOB), peso médio individual $(\mathrm{PMI})$ e produto peso versus sobrevivência $(\mathrm{P} \times \mathrm{S})$.

\begin{tabular}{|c|c|c|c|c|c|c|c|c|c|c|}
\hline & \multicolumn{2}{|c|}{$\mathrm{T} 1$} & \multicolumn{2}{|c|}{$\mathrm{T} 2$} & \multicolumn{2}{|c|}{ T3 } & \multicolumn{2}{|c|}{$\mathrm{T} 4$} & \multicolumn{2}{|c|}{ T5 } \\
\hline & $\mathrm{CT}$ & $\mathrm{CP}$ & CT & $\mathrm{CP}$ & $\mathrm{CT}$ & $\mathrm{CP}$ & CT & $\mathrm{CP}$ & CT & $\mathrm{CP}$ \\
\hline \multicolumn{11}{|c|}{$\begin{array}{l}\text { Comprimento } \\
\text { (mm) }\end{array}$} \\
\hline Dia 0 & 5,5 & 5,0 & 5,5 & 5,0 & 5,5 & 5,0 & 5,5 & 5,0 & 5,5 & 5,0 \\
\hline Dia 7 & 8,7 & 7,7 & 8,8 & 7,8 & 8,8 & 7,5 & 7,8 & 6,8 & 7,3 & 6,3 \\
\hline Dia 14 & 19,8 & 17,8 & 19,2 & 17,5 & 17,1 & 15,1 & 14,8 & 12,8 & 8,7 & 7,7 \\
\hline Dia 21 & 31,8 & 27,3 & 28,8 & 25,1 & 24,7 & 21,7 & 18,0 & 15,2 & 10,5 & 9,3 \\
\hline SOB $(\%)$ & \multicolumn{2}{|c|}{51,76} & \multicolumn{2}{|c|}{84,70} & \multicolumn{2}{|c|}{88,81} & \multicolumn{2}{|c|}{92,15} & \multicolumn{2}{|c|}{66,66} \\
\hline PMI(mg) & \multicolumn{2}{|c|}{122,36} & \multicolumn{2}{|c|}{118,44} & \multicolumn{2}{|c|}{100,63} & \multicolumn{2}{|c|}{54,37} & \multicolumn{2}{|c|}{20,72} \\
\hline$P \times S$ & \multicolumn{2}{|c|}{63,32} & \multicolumn{2}{|c|}{101,02} & \multicolumn{2}{|c|}{89,16} & \multicolumn{2}{|c|}{50,12} & \multicolumn{2}{|c|}{13,71} \\
\hline
\end{tabular}

LEGENDRE et al. (1995) usando alimento à base de $30 \%$ fígado mais $50 \%$ levedura e 7,5\% de lipídios obtiveram peso médio aos 14 dias de $114 \mathrm{mg}$. Este resultado nos leva a avaliar o efeito de lipídios (ácidos graxos) em alimentos para larvas de jundiá, proximamente.

A relação peso $x$ sobrevivência aumentou 4,057 a mais a cada $1 \%$ de proteína na ração até o nível de $37,66 \%$ PB do tratamento T2. Para o T1 (41,44\% PB) esta relação foi menor, devido à sobrevivência mais baixa, levando-nos a buscar no futuro, outras alternativas protéicas para substituir o fígado bovino fresco em dietas secas em proporções próximas ao tratamento $\mathrm{T} 2$. hipóteses relacionado comprimento total e padrão (CT, CP) mm, sobrevivência (SOB) em \%, peso individual (PMI) em g e peso versus sobrevivência de larvvas do jundiá Rhamdia quelen.

\begin{tabular}{lcccc}
\hline VARIÁVEIS & b0 & b1 & $F$ & PROB $<$ \\
& & & & \\
\hline & & & & \\
CT7 & 4,93 & 0,099 & 18,29 & 0,0009 \\
CP7 & 3,86 & 0,099 & 37,45 & 0,0001 \\
CT14 & $-8,42$ & 0,717 & 89,95 & 0,0001 \\
CP14 & $-8,63$ & 0,672 & 106,03 & 0,0001 \\
CT21 & $-26,22$ & 1,443 & 238,95 & 0,0001 \\
CP21 & $-22,36$ & 1,238 & 238,20 & 0,0001 \\
SOB(21) & 111,01 & $-1,006$ & 1,54 & 0,236 \\
PMI(21) & $-162,065$ & 7,225 & 101,173 & 0,0001 \\
PxS(21) & $-74,32$ & 4,057 & 10,268 & 0,069 \\
& & & & \\
\hline
\end{tabular}

RADÜNZ NETO et al. (1993) utilizando $80 \%$ de levedura em três experimentos com larvas de Cyprinus carpio quando obtiveram 92, 96 e 99\% de sobrevivência.

$\mathrm{O}$ peso médio das larvas foi sensivelmente influenciado pelo nível de PB nos alimentos havendo um aumento de $7,225 \mathrm{mg}$ para cada $1 \%$ de proteína a mais na ração obtendo-se um PMI de 122,36mg para o tratamento T1 (50\% levedura) e $20,72 \mathrm{mg}$ para o tratamento T5 (90\% levedura; Tabela 2). Todos os alimentos constituídos da mistura levedura mais fígado resultaram em larvas muito maiores que aquelas obtidas por SANTOS et al. (1988), com fígado mais ração, com $10 \mathrm{~mm}$ de CT e $21 \mathrm{mg}$ aos 30 dias. Para outra espécie de bagre (Heterobranchus longifilis),
Os resultados do presente trabalho, quando
comparados com aqueles obtidos por SANTOS et al. (1988) (P x S = 21mg x 36,57\% = 7,6) são satisfatórios e servirão de base para novas avaliações sobre e lipídios (ácidos graxos) para larvas de jundiá (Rhamdia quelen).

\section{CONCLUSÃO}

Dentro dos limites de proteína bruta estudados há efeito positivo de níveis mais elevados de proteína bruta sobre os comprimentos total e padrão e peso individual, porém há um efeito negativo sobre a sobrevivência das larvas do jundiá Rhamdia quelen.

\section{REFERÊNCIAS BIBLIOGRÁFICAS}

CHARLON, N., BERGOT, P. Rearing system for feeding fish larvae on dry diets. Trial with carp (Cyprinus carpio, L.) larvae. Aquaculture, n. 41, p. 1-9, 1984.

CHURCH, D.C., POND, W.G. Basic animal nutrition and feeding. Church, 1974. 300 p.

FIALHO, E.T. Tabela de composição química e valores energéticos de alimentos para suínos. Concórdia, SC, EMBRAPA-CNPSA, 1983. (Documentos $n^{\circ}$ 6) 23 p.

HEPHER, B. Nutrition of pond fishes. Cambridge Univ. Press, Inglaterra, $1990.388 \mathrm{p}$. of nutrition and feeding of fish larvae. 1988. Sept 19-23. Seminar on "Acuacultura Marina". 14 p. requerimentos em aminoácidos essenciais, vitaminas

KAUSHIK, S.J. Major constraints and recent advances in the field 
LEGENDRE, M., KERDCHUEN, N., CORRAZE, G. et al. Larval rearing of an African catfish Heterobranchus longifilis (Teleostei, Clariidae): effect of dietary lipids on growth, survival and fatty acid composition of fry. Aquat Living Resour, n. 8, p. 355-363, 1995.

LI, J., LOVELL, R.T. Elevated levels of dietary ascorbic acid increase immune responses in channel catfish. J Nutr, Auburn, v. 115, n. 1, p. $123-131,1985$

LUCHINI, L., SALAS, T. Preliminary data on larval survival of South American catfish, Rhamdia sapo. Aquaculture, n. 42, p. $175-177,1984$

PIAIA, R., ULIANA, O., FILIPETTO, et $\boldsymbol{a l}$. Efeito de diferentes fontes protéicas no crescimento e sobrevivência durante a primeira fase larval do jundia Rhamdia quelen. In: II JORNADA INTEGRADA DE PESQUISA, EXTENSÃO E ENSINO, 1995, Santa Maria, RS. Anais... Pró-Reitoria de Pós-graduação e Pesquisa, 1995. p. 528.

RADÜNZ NETO, J., CHARLON, N., ESCAFFRE, A.M. et al. Effet de l'huile de foie de morue sur la survie et la croissance des larves de cyprinides (Carassuis auratus L., Cyprinus carpio L.). Fish Nutrition in Pratice Biarritz (France). p. 541-550 June 24-27, 1993. Paris: INRA (Les colloques, $n^{\circ} 61$ ).
SANTOS, A.B., CHWA, E.Q., THOMPSON, D.M. Produção e criação de alevinos de Rhamdia sapo Valenciennes, 1840. In: VI SIMPÓSIO LATINOAMERICANO E V SIMPÓSIO BRASILEIRO DE AQUICULTURA, 1988, Florianópolis, SC. Anais... Florianópolis, 1988. p. 615620 .

SAS - Statistical Analysis System. User's Guide. Version 6, SAS INSTITUTE INC. 4. ed. North Caroline: SAS INSTITUTE INC., 1989, 846 p.

SZLAMINSKA, M., ESCAFFRE, A., DURANTE, H. et al. Casein in the place of beef liver in artificial diets for common carp (Cyprinus carpio, L.) larvae. Aquat Living Resour, n. 3, p. 229-234, 1990. INRA.

SZLAMINSKA, M., ESCAFFRE, A., CHARLON, N. et al Preliminary data on semisynthetic diets for goldfish (Carassius auratus L.) larvae. Fish Nutrition Pratice Biarritz (France), p. 607-612, june 24-27, 1991.

VARELA, Z., FABIANO, G., FISCHER, K. Cria de larvas de bagre negro (Rhamdia sapo, Valenciennes) en el laboratorio. Resumenes comun. Ciências naturales, INSN, Montevideo. Uruguai. 1983. no 3, p. 117-118. 